\title{
MEASURING SOCIAL LICENSE TO OPERATE THE INFRASTRUCTURE PROJECT IN BANGLADESH
}

\author{
Md Manjur Morshed*, Zaki Arafin and Salima Khan Nafi \\ Department of Urban and Regional Planning, Khulna University of Engineering \& Technology, Bangladesh
}

Received: 11 March 2021

Accepted: 10 May 2021

\begin{abstract}
Social license to operate is a measure to engage with and gain acceptance from the stakeholders for large infrastructure projects. The object of this study is to measure social license to operate an infrastructure project in Khulna city, Bangladesh. Predicated on an established model, 16 statements were selected as the basis for measuring the social license to operate. A questionnaire survey was conducted among 44 local stakeholders. Using varimax rotation, five different components were identified: socio-political, economic, procedural fairness, interactional trust, and institutional trust. The model was statistically tested and found to be a medium fit explaining the results. The findings are that the project has gained socio-political, economic, procedural fairness, and interactional trust of the stakeholders, yet lacks institutional trust factor to achieve a social license to operate. The paper recommends the inclusion of the social license to operate concept in infrastructure planning and implementation phases in Bangladesh.
\end{abstract}

Keywords: Factor Loading; Legitimacy; Principal Component Analysis; Project; Stakeholder.

\section{INTRODUCTION}

The concept of social license to operate (SLO) is traditionally focused on local people directly or indirectly affected by any project. As a response to social risk, the term SLO emerged in the mid-1990s from the mining companies (Boutilier and Thomson, 2011). From that time, the term had been used by a wide range of actors in the resource sector including many development sectors like mining, civil society and NGOs, research institutions, governments and consultants (BHPB, 2011; Kurlander, 2001; Slack, 2009; CSIRO, 2013; McNab et al., 2013; Australian Government, 2006). Therefore, SLO is used to describe the acceptance or approval of an ongoing project by local community members and other stakeholders (Moffat and Zhang, 2017).

Infrastructure is considered is the key to Bangladesh's rapid economic development. Several mega-projects e.g., Padma bridge, nuclear power plant, CNG terminal, etc. are providing a boost for the country's drive for rapid economic development. For accelerating growth and empowering citizens in its national development strategies, such as the Five Year Plan (FYP), Bangladesh has identified access to infrastructure services as a major component of development. According to the $7^{\text {th }}$ FYP, the country needs more than five percent of GDP as an additional investment on major infrastructure development projects annually. To achieve the SDG targets (infrastructure-related), additional cost has been estimated to be 5.67\% up to the fiscal year 2030 (GED, 2017).

The southwestern part of Bangladesh, namely the Khulna division, is expected to get the impetus for economic activity with the development of Mongla port, Padma bridge connecting Dhaka, railway line connecting DhakaKhulna-Kolkata (India), and road connections to the Asian highway. As part of these mega-infrastructure projects, connecting Khulna railway station with the Asian Highway has been a key infrastructure project. To improve the network infrastructure, the Khulna railway station had been remodeled and Khulna-Mongla railway project was passed by ECNEC on 21 December 2010.

As part of the overall infrastructure, road from the Railway station connecting the Asian highway (covering Gollamari and zero-point intersection) needs to be improved and a road expansion program has been undertaken by Local Government and Engineering Departments (LGED). For the expansion, land acquisition as well as eviction from the public land is mandatory. Infrastructure development project like this where peoples' land will be acquired, and they are subject to eviction, need to measure the SLO for better acceptance of the development project by the local community.

The objective of this research is to measure SLO for the road expansion project in Khulna city in order to measure to see how the project is been received by the local stakeholders. This paper explores the application of 
Thomson and Boutilier model, which is one of the most noted methods of measuring SLO, in Bangladesh contexts. Measuring SLO is a challenging task in a developing country context like Bangladesh as concepts such as consensus building, public participation, and resettlement and rehabilitation are rarely considered in the project conception and implementation phases. One of the major limitations of this study is that it assesses SLO of an ongoing infrastructure project, and thus does not consider phases of the project, i.e. conception or implementation. Secondly, a small number of directly project-affected stakeholders are selected for the questionnaire survey. Against this background, the second section of the paper explains different aspects of SLO. The third section is materials and methods. The fourth section is findings and followed by a discussion in the fifth section. The concluding remarks are in the sixth section.

\section{THE CONCEPT OF SLO}

The SLO concept is a measure to justify large infrastructure investment and activities, and modeling and measuring SLO is a pre-condition for any successful project initiation. Over the last decade, there has been increasing recognition of the SLO to ensure societal support for extractive operations, i.e., mining, which predicated on avoiding protests by the local community and ensuring long-term project sustainability (Hanna, 2016; Mitchel, 2020). The SLO guidelines and criteria noted by different literature include legitimacy, credibility, and trust by the stakeholders (Boutilier, 2014; Jijelava and Vanclay, 2018; Vanclay, 2017). On the contrary, different literature also noted the ambiguity of the SLO concept (see for example, Owen and Kemp, 2013; Harvey and Bice, 2014; De Jong and Humphreys, 2016).

Meesters et al. (2020) summarized the key problems of the SLO concept and its applicability. Firstly, overwhelming literature limit the stakeholders' engagement to locals who live nearby and to vocal and organized groups while ignoring the non-residents. Secondly, stakeholders' engagement is objective as to run the operation smoothly which is not necessarily inclusive, but can be limited to powerful interest groups only. Thirdly, the SLO concept is more concerned with the local socio-economic and environmental impacts while ignoring the global consequences. This, however, opens up a new concern with the capacity of the local stakeholders in the hegemonic environment. However, prioritizing local stakeholders in SLO is convenient as opposed to considering non-locals and global implications.

The pioneering work by Thomson and Boutilier (2011) defined SLO as the community's or stakeholders' perceptions regarding the acceptability of a government's local operations i.e. development projects like road expansion. They identified four levels of the SLO: i) withheld/withdrawn; ii) acceptance; iii) approval; and iv) psychological identification. The hypothesis is that that SLO granted by stakeholders to a government/company is inversely correlated to the level of socio-political risks and vis-à-vis. The lowest level of SLO signifies that the project is being withheld or withdrawn, meaning the project is in danger of accessing public support, access to resources and labor, and in many cases, there is a problem of mass-protest. Therefore, the lowest level of SLO indicates an extremely high socio-political risk. On the contrary, the highest level of SLO is the acceptance of the project. On figure 1, the acceptance of the project covers the highest area which indicates that it is the common level of the social license granted. If trust is established over time, the SLO could rise to the highest level - psychological identification, where the level of socio-political risks is very low.

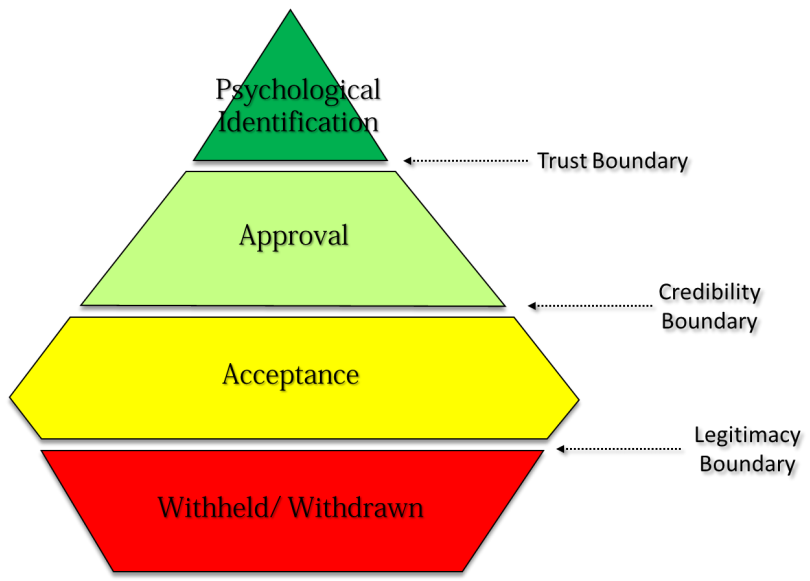

Figure1: Levels of SLO (Adapted from Thomson and Boutilier, 2011)

Generally, SLO is measure qualitatively with a pool of statements devised to measure the four-level concept of SLO (Thomson and Boutilier, 2011). The whole set of analyses is validated against the verbal opinion 
(agree/disagree ratings at a 5-point scale) from stakeholders on the project. By applying a varimax factor rotation analysis, four factors (economic legitimacy, socio-political legitimacy, interactional trust, and institutionalized trust) are measured, and then an arrowhead model is proposed. In the arrowhead model, the four factors had been measured independently by the same statements. The average of the ratings on the statements symbolizes the idea that the overall level of SLO is a continuum. A high score on the perception of institutionalized trust will always have a high score on other factors. Stakeholders with low scores on the perception of socio-political legitimacy and interactional trust will never have high scores on institutionalized trust. Likewise, stakeholders with low scores on perceptions of economic legitimacy will never have high scores in any of the other factors according to the arrowhead model.

\section{METHODOLOGY}

\subsection{Study Area}

The study area is Khulna city, the third-largest city in Bangladesh. For measuring SLO, selection of study area was a crucial task as the project needed to have many interactions with the local people and the stakeholders. The road expansion projection from the powerhouse intersection to Gollamari, which is directly linked to the Khulna-Mongla highway, is considered for this study. Recently improved Khulna railway station is located just beside the powerhouse. In this situation, the railway station will face a huge traffic load from Mongla for being the second largest seaport in the country. The project road is Sher-e-Bangla road-1. A portion of the road expansion, from powerhouse to Gollamari is the area of this research. The Khulna Roads and Highways (RHD) is responsible for the construction work, which plans to expand the two-lane roads into four lanes. The construction has started on 17 October, 2020 after a brief halt due to technical difficulties and currently ongoing.

The road expansion project is part of the 24 mega-projects that are to shape the future of Khulna city. The cost is around 250 crore. The ongoing project is causing a severe problem for traffic congestions, as well as demolition of illegal structures. The Khulna City Corporation (KCC) is overseeing the clearance activities as well as removing and relocating existing urban infrastructure from the project area (Dhaka Tribune, 2020). The project area is shown in figure 2 .

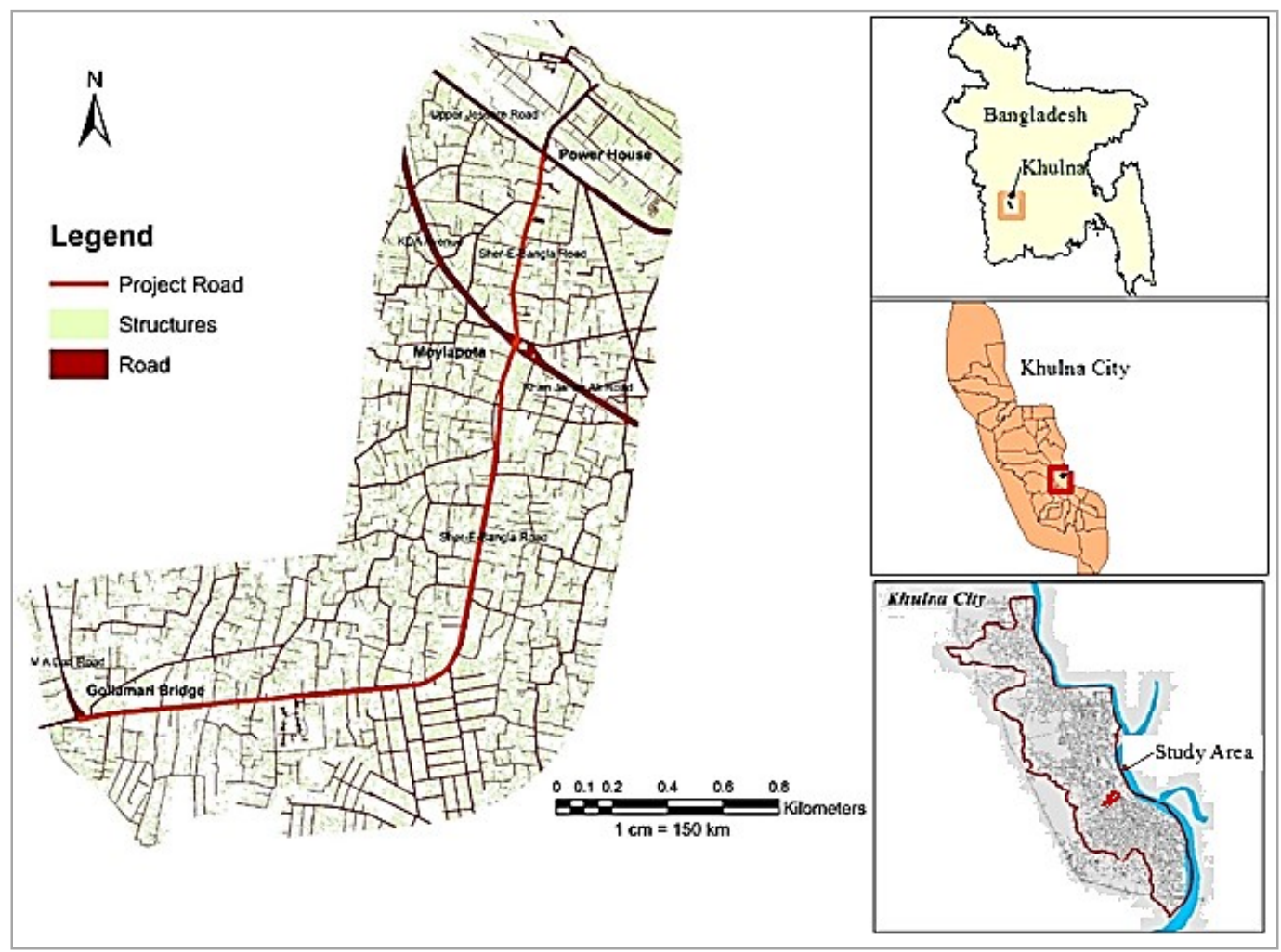

Figure 2: Study area map (powerhouse to Gollamari Bridge) 


\subsection{Stakeholders and Sample Selection}

Stakeholders represent the whole community who are affected directly or indirectly by the project activity. In a broader sense, stakeholders are those who could be affected by the actions of a company or who could have an effect on the company of the development project. Thus, there are many stakeholder networks outside a geographic community, and for measuring the SLO, they also need to be included. The selected infrastructure development project of this research has many stakeholders: local community, drivers, landowners, daylaborers, traffic police, and so on. The industry association, local shops, residents, motor association, drivers (heavy, medium, light), authority, local institute, community organizations of the area are also directly or indirectly affected due to this construction project, who are the major stakeholders for this study.

For this study, a total of 44 local people who lived or worked in the study area within the proximity of the construction site were selected randomly for primary data collection and questionnaire survey. The stakeholders are comprised of: 9 landowners, 5 residential renters, 7 small shop owners, 6 battery-bike drivers and 6 commuters, 3 rickshaw pullers, 4 truck drivers, 2 police officers and 2 illegal occupiers (food sellers). These stakeholders are directly and indirectly affected due to the road construction project. However, understandably, there are many more project stakeholders which are not considered due to lack of data collection. Because of the time limitation of the research (funding period between July 2018 to June 2020), as well as a mere lack of cooperation from the stakeholders, a statistically representative sampling was not possible. However, the limited sample size does not put a constraint to testing the applicability of the model for the case study.

\subsection{Statements Selection}

After selecting the stakeholders, from a pool of various statements related to the stakeholders, 16 were finally selected. These statements had followed Thomson and Boutilier's statements and were selected through psychometric item selection process after discussion with the key stakeholders. The statements are as follows:

1. Our organization and the infrastructure project have the same vision for the future of this area.

2. The construction project does what it says will do in its relation with the locality.

3. This project is not harmful to our local tradition/culture.

4. This project keeps harmony with the day-to-day life of the local community.

5. This project shares decision-making with the community.

6. The infrastructure project takes account of our interests.

7. There was consultation with the locality before initiating the project.

8. This project will create problems related to the environment and others.

9. In the long run, the project contributes to the well-being of the whole region.

10. The total cost of transportation will be decreased.

11. The project authority has taken mitigating measures to negatively affected people.

12. The project will decrease traffic congestion as well as accidents.

13. Land price and house Rent will increase because of the road project.

14. The budget and the construction progress of the project seem fair to me.

15. The infrastructure project treats everyone fairly.

16. I think the project has SLO in our locality.

\subsection{Data Analysis}

The collected data was inputted into SPSS 21 and AMOS 21 software to run the path model and factor analysis. All the statements were asked to the stakeholders as they were requested to respond on a scale of 5 points $(1=$ strongly disagree, $5=$ strongly agree). The principal component analysis was performed with varimax rotation to determine the factor affecting SLO.

A varimax matrix is created to show the correlation among the statements where high scores indicate a highly positive review and vice versa. The rotated component matrix shows the Pearson correlation between the items, the statements and the components. These correlations are known as factor loadings. Ideally, this technique is used to measure each input variable precisely as one factor. But there are also four cross-loadings here. These cross-loadings are then redistributed over the factors. Among many rotation techniques, varimax rotation, short for variable maximization is been used here. It tries to redistribute the factor loadings in such a way that each variable measures precisely one factor. AMOS software is used to test the path diagram of the SLO of the area. The path model provides the result of excellent fitness of the statements with significant and non-significant value. 


\section{RESULTS AND DISCUSSIONS}

\subsection{Principal Component Analysis}

With the 15 input variables, that are our statements, principal component analysis initially extracts 16 statements (or "components"). In every factor analysis, there is the same number of factors as there are variables. Each factor captures a certain amount of the overall variance in the observed variables, and the factors are always listed in the order of how much variation they explain. The eigenvalue is a measure of how much of the variance of the observed variables a factor explains. Only the components with high eigenvalues $(>1)$ are likely to represent real underlying factors.

A varimax matrix with all the selected statements which tend to produce factor loading is used to simplify the expression of a particular factor in terms of a few major items. That means each factor has a small number of large loadings. The output of the principal component factor analysis with varimax rotation is shown in table 1.

From table 1, it is seen that the 15 statements can be categorized, and are named accordingly, into five components that are affecting the SLO of the road expansion project. The factors are: i) socio-political legitimacy, ii) procedural fairness, iii) economic legitimacy, iv) interactional trust; and v) institutionalized trust. These factors are being measured with the statements which had been scaled down and surveyed on the stakeholders. These are described in the path diagram in figure 2

Table 1: Rotated component matrix.

\begin{tabular}{|c|c|c|c|c|c|}
\hline & \multicolumn{5}{|c|}{ Component } \\
\hline & $\begin{array}{c}\text { Socio- } \\
\text { political } \\
\text { legitimacy }\end{array}$ & $\begin{array}{l}\text { Procedural } \\
\text { fairness }\end{array}$ & $\begin{array}{l}\text { Economic } \\
\text { legitimacy }\end{array}$ & $\begin{array}{l}\text { Interaction } \\
\text { al trust }\end{array}$ & $\begin{array}{l}\text { Institution } \\
\text { al trust }\end{array}$ \\
\hline $\begin{array}{l}\text { This project keeps harmony with the day } \\
\text { to day life of the local community }\end{array}$ & 0.735 & & & & \\
\hline Compatible with the locality & 0.700 & & & & \\
\hline The project has same vision for the future & 0.621 & & -0.431 & & \\
\hline $\begin{array}{l}\text { This project accounts for the interest of } \\
\text { the community }\end{array}$ & & 0.749 & & & \\
\hline $\begin{array}{l}\text { The project activities are done in } \\
\text { consultation with community }\end{array}$ & & 0.677 & & & \\
\hline $\begin{array}{l}\text { The project is fair in budgeting and the } \\
\text { construction process }\end{array}$ & & 0.551 & & & \\
\hline $\begin{array}{l}\text { The project will decrease traffic } \\
\text { congestion as well as accidents }\end{array}$ & & 0.535 & & 0.530 & \\
\hline $\begin{array}{l}\text { The project shares decision-making with } \\
\text { the community }\end{array}$ & & 0.445 & & & \\
\hline $\begin{array}{l}\text { Land price and house rent will increase in } \\
\text { the locality }\end{array}$ & & & 0.793 & & \\
\hline Transportation cost will be decreased & & & 0.651 & & \\
\hline $\begin{array}{l}\text { Mitigating measures for the negatively } \\
\text { affected people }\end{array}$ & -0.465 & & -0.621 & & \\
\hline $\begin{array}{l}\text { Will not create environmental and other } \\
\text { problems }\end{array}$ & & & & 0.712 & 0.413 \\
\hline $\begin{array}{l}\text { The project is not harmful for the local } \\
\text { tradition/culture }\end{array}$ & & & & 0.638 & \\
\hline The project treats everyone fairly & & & & -0.546 & \\
\hline $\begin{array}{l}\text { The project will bring wellbeing to the } \\
\text { whole region }\end{array}$ & & & & & 0.862 \\
\hline
\end{tabular}




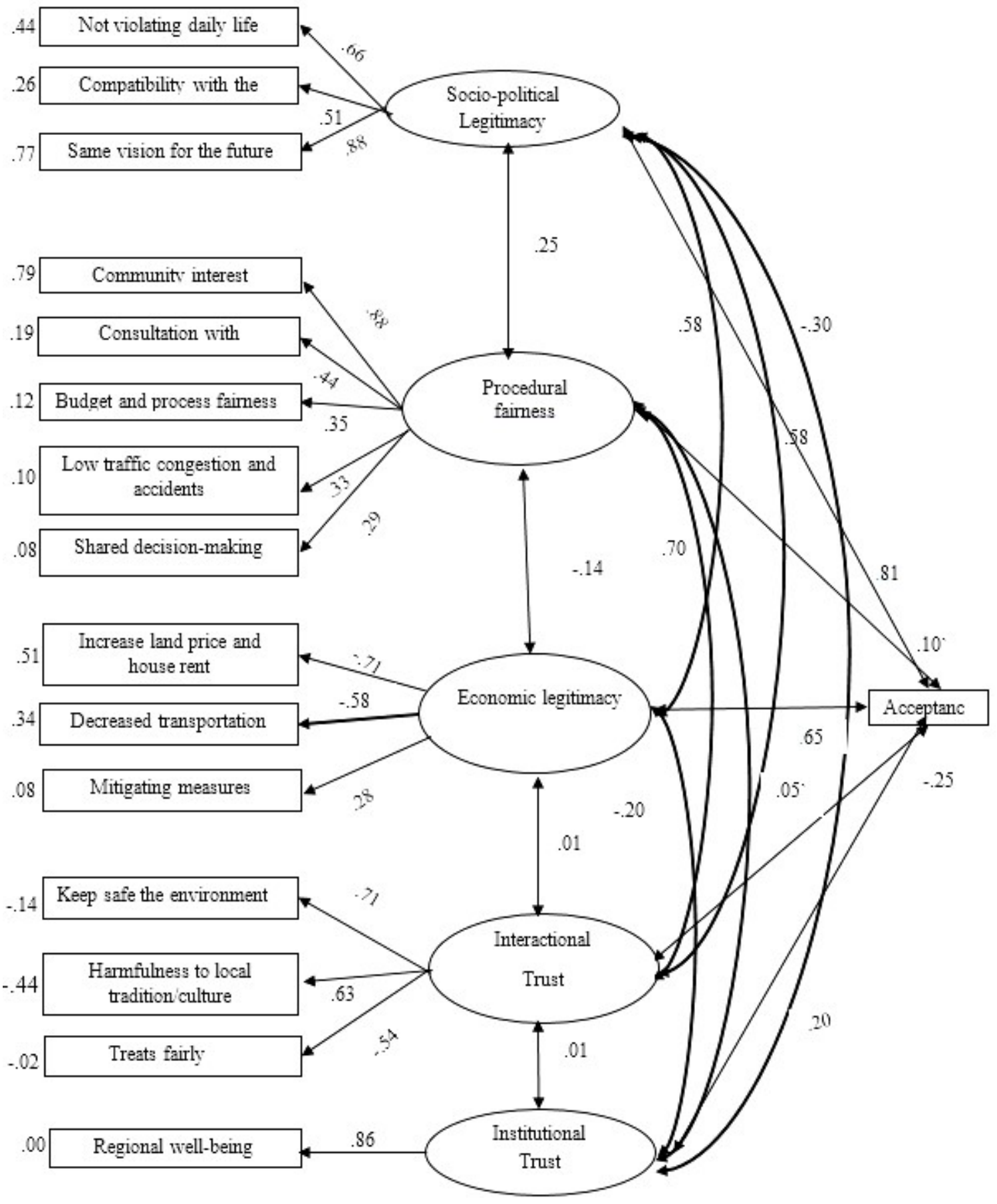

Figure 2: Path diagram

\subsection{Path Analysis}

To investigate the independent relationships more systematically between the variables, the path analysis is performed. Using SPSS AMOS 21, the path model was run and analyzed. For having a small sample size, item scores for each variable had been averaged and used as an observed variable in the model. The path diagram presents the model with all the correlations among the statements and factors with errors as well as a relation among the factors. From the Path Diagram, it is seen that all the five factors are representing their relations with the acceptance of the road expansion project and with the selected statements also. The model data had been standardized to relate the factors to the acceptance of the project. Among all the five factors, the only 
institutional trust had shown negative loading (-0.25), which means the stakeholders of the locality are declining the project for not fulfilling their institutional trust. This factor is highly dependent on the regional wellbeing statement.

Among all the factors, the socio-political legitimacy has shown the highest relationship with acceptance $(0.81)$. The factor itself depends on three statements and all of them have shown positive loading. The factor is related to the other factors also. Even though the relation of socio-political legitimacy with institutional trust is negative, the other factors have positive relation over this factor. This represents that, the expansion project is gaining SLO over socio-political legitimacy. The second most related factor to the acceptance is economic legitimacy with 0.65 value. Though two of the statements have shown negative loading with the factor, the relation with the acceptance is positive. This represents that the stakeholders are accepting the expansion project in their locality. Economic legitimacy has shown positive relation with socio-political legitimacy and Interactional trust. For not having proper institutional trust and procedural fairness, stakeholders are giving low acceptance over the economic legitimacy. When it comes to procedural fairness and interactional trust factor, both of them have shown positive relations with the acceptance of the project $(0.10$ and 0.05$)$. Procedural fairness has shown positive loading with all the 5 statements under it (gained from factor analysis). On the other hand, interactional trust has shown relation with two statements negatively and one positively. Though the relation is low, the stakeholders are positive to SLO over these two factors.

\subsection{Model Fitness}

The goodness of fit of the path model had been assessed using Chi-square test, the comparative fit index (CFI), normed fit index (NFI) and root mean error of approximation (RMSEA) (Hu and Bentler, 1999; Kenny and McCoach, 2003).

Chi-square statistics had been used for non-significant values. However, Chi-square statistics remains significant and thus absolute fit index and incremental fit index need to be checked. SPSS AMOS 21 calculate goodness of fit and badness of fit automatically. On the other hand, for incremental fit index, RMR, GFI, CFI, AGFI, NFL test have been checked for badness of fit. For Absolute fit index, RMSEA (root mean square error of approximation) is been checked in this study.

\subsection{Chi-square Statistics}

The saturated model shows the best result and the independence model represent the worst result of a model (Table 2). NPAR is the number of parameters in the model. In the saturated model, there are 136 parameters. For the tested (default) model there are 45 parameters. For the independence model, there are 16 parameters where all of the paths have been deleted. CMIN is the actual magnitude and DF is the degree of freedom. The chi-square value is called CMIN. If the chi-square value is significant, the model is regarded as valid. If CMIN/DF is less than 3.00 then the indicators of model fitness will be good. The value of CMIN/DF of this default model is 1.192, which is less than 3.00 and it represents a good fitness of the model.

Table 2: NPAR, CMIN, DF \& CMIN/DF of the model

\begin{tabular}{lrrrrr}
\hline Model & NPAR & CMIN & DF & P & CMIN/DF \\
\hline Default model & 45 & 108.499 & 91 & 0.102 & 1.192 \\
Saturated model & 136 & 0.000 & 0 & & \\
Independence model & 16 & 247.132 & 120 & 0.000 & 2.059 \\
\hline
\end{tabular}

\subsection{RMR, GFI, CFI and NFI}

RMR indicates the badness of fit and GFI shows the goodness fit of a model. The root mean square residual (RMR) is an index of the amount by which the estimated (by tested model) variance and covariance differ from the observed variance and covariance. For the saturated model, it will be a perfect 0 and 0.05 will be tolerable but not more than 0.1 . The standardized RMR should be equal to or less than 0.10 for "a good fitting" model. In this tested model, the value of RMR is 0.10 which showed a moderate fitness of the model.

GFI, the goodness of fit index, is the proportion of the variance in the sample variance, and the covariance matrix is accounted for by the model. GFI varies from 0 to 1 but theoretically can yield meaningless negative values. GFI deals with errors in reproducing the variance-covariance matrix. GFI often runs high compared to fit model, using 0.95 as the cutoff, more than 0.95 gives the best result of a model. GFI should be equal to or 
greater than 0.90 to accept the model. But value between 0.80 and 0.90 of GFI value is also granted and accepted as moderate fit.

AGFI (adjusted GFI) is an alternate GFI index in which the value of the index is adjusted for the number of parameters in the model. The value of AGFI is always less than GFI and the AGFI of the default model is 0.70 . PGFI ( $\mathrm{p}$ is for parsimony), the index is adjusted to reward simple models and penalized models in which few paths have been deleted (Table 3).

Table 3: RMR, GFI, AGFI, PGFI, NFI and CFI of the model

\begin{tabular}{ccccccc}
\hline Model & RMR & GFI & AGFI & PGFI & $\begin{array}{c}\text { NFI } \\
\text { Delta1 }\end{array}$ & CFI \\
\hline Default model & 0.107 & 0.800 & 0.701 & 0.535 & 0.561 & 0.862 \\
Saturated model & 0.000 & 1.000 & & & 1.000 & 1.000 \\
Independence model & 0.185 & 0.559 & 0.500 & 0.493 & 0.000 & 0.000 \\
\hline
\end{tabular}

This goodness of fit indices compares the tested model to the independent model rather than to the saturated model. The normed fit index (NFI) is simply the difference between the two models' chi-squares divided by the chi-square for the independence model. For our data, that is 0.56 . Value of 0.9 or higher indicates a good fit. But the value of NFI of this model does not indicate a good fit. The comparative fit index (CFI) uses a similar approach (with a noncentral chi-square) and is said to be a good index. It ranges from 0 to 1 , like the NFI, and 0.95 (or 0.9 or higher) indicates a good fit. The CFI value of the default model is 0.86 which seems be a moderate fitness of the model (Table 3 ).

\subsection{RMSEA}

The root mean square error of approximation (RMSEA) estimates lack of fitness compared to the saturated model. RMSEA of 0.05 or less indicates a good fit and 0.08 or less adequate fit. LO 90 and HI 90 are the lower and upper ends of a $90 \%$ confidence interval on this estimate. PCLOSE is the p-value testing the null that RMSEA is no greater than 0.05. RMSEA value of this tested model is 0.06 , meaning the model is tolerable and indicating a moderately good fit (Table 4).

Table 4: Root mean square error of approximation (RMSEA) of the model

\begin{tabular}{lrrrr}
\hline Model & RMSEA & LO 90 & HI 90 & PCLOSE \\
\hline Default model & 0.067 & 0.000 & 0.111 & 0.290 \\
Independence model & 0.157 & 0.129 & 0.185 & 0.000 \\
\hline
\end{tabular}

\section{DISCUSSION}

Among the five factors, socio-political legitimacy is comprised of three statements defining the SLO (Table 1). All the statements have positive loadings. However, the project is able to be in harmony with the day-to-day life of the community has the highest factor loading $(0.735)$. This is followed by project compatibility with the locality (0.7) and by the similarity of vision for the future between the stakeholders $(0.621)$. However, when comes to the project's economic legitimacy, the similarity of vision has negative loading $(-0.431)$, meaning that people are not convinced that the project will benefit economic benefit for all stakeholders. Musiyarira et al. (2020) highlight the key challenges of securing SLO in developing country context, where companies engaged in project activities grossly ignore SLO and secure projects through lobbying resulting in massive corruption. The above findings that the project stakeholders aspire for such development project, they are not convinced of personal economic benefit from the road expansion project.

Secondly, the procedural fairness has a total of 5 statements. Accounting for the interest of the community (0.749), having proper consultation while implementing the project activities (0.677), fairness in the budget and construction process $(0.551)$, decreasing traffic congestion $(0.535)$, and sharing decision making with the community $(0.445)$ - all these have shown positive loadings. These indicate that the project is getting SLO over procedural fairness. The road expansion project will decrease traffic congestion, as well as accidents, has shown a positive loading in the interactional trust factor also $(0.530)$, which has almost the same loading as the procedural fairness. This indicates that people are taking decreasing traffic congestion as positivity of the road expansion project. However, road expansion projects can have broader consequences such as, increasing traffic volume as it connects the Asian highway and Khulna railway station, and loss of local jobs. Therefore, broader 
consequences of infrastructure projects are often out-of-sight which the local stakeholders fail to appreciate (see also, Brueckner and Eabrasu, 2018).

Thirdly, three statements underline the economic legitimacy factor and two of those have shown positives whereas one negative loading. Land price and house rent will gain a significant boost (0.793) and transportation cost will be decreased (0.651) show that people are accepting the road expansion project in their locality. However, mitigating measures for the negatively affected people have negative loading, an indication that the project has less socio-political and economic legitimacy. From the in-depth survey, it was found that very few measures are taken to remedy, such as resettlement and rehabilitation, due to eviction caused by the road expansion project. However, as a whole, the project has SLO in terms of economic legitimacy.

Fourthly, three statements have shown loadings under the interactional trust. Among those three, the project will not create environmental and other problems (0.712) and not harmful to the local tradition/culture (0.638) have shown positive relation with the interactional trust factor. However, fair treatment by the road expansion in terms of eviction and resettlement received negative factor loading. Such negative loading is an indication that project stakeholders are restrained to approve the project due to the biases in treatment by the implementing authority.

Finally, the institutional trust, that is, the project will bring wellbeing to the whole region (0.862). The project stakeholders are accepting the expansion project over this statement and relying on the institutionalized trust factor. Another factor that has shown positive loading is that the project will not create environmental and other problems (0.413), thus reflecting positive SLO of the road expansion project. However, such positivity can also be related to a lack of awareness among the stakeholders as the project is expected to generate larger traffic volume (see also, Brueckner and Eabrasu, 2018).

\section{CONCLUSIONS}

In this research we have used the Thomson Boutilier model to identify major factors affecting the SLO of a road expansion project in Khulna city, Bangladesh. The study suggests that socio-political legitimacy, procedural fairness, economic legitimacy, interactional trust and institutional trust determine the SLO of the project. The varimax rotated component matrix has shown the dependency of the statements on various factors. Secondly, the path diagram presented all the co-relations with the factors and the acceptance of the project by the stakeholders. socio-political legitimacy has shown the highest determinant for SLO of the project. The project has also achieved economic legitimacy, procedural fairness and interactional trust of the stakeholders. However, the project has failed to achieve institutional trust, which is also negatively co-related to economic legitimacy. In conclusion, the project needs to gain institutional trust for higher SLO.

SLO is not a commonly used tool for infrastructure projects in Bangladesh. This paper has presented a model for understanding SLO with limited data. A comprehensive data collection can significantly improve the model, thus can be used as a tool for large infrastructure projects in Bangladesh. Additionally, including the SLO concept in the project planning and implementation phase can significantly improve the sustainability of infrastructure projects in Bangladesh.

\section{ACKNOWLEDGEMENT}

This research project was funded by the UGC-KUET research grant. The first author was the principal investigator. The second author worked as a research assistant during the project period. The third author collected data as well as did her bachelor dissertation on this very topic, thus making this publication a part of her dissertation. We thank the stakeholders who participated in the questionnaire survey. We acknowledge the two anonymous reviewers and Editor of Journal of Engineering Science for their support in the publication process.

\section{REFERENCES}

Australian Government, 2006. Community Engagement and Development: Leading Practice Sustainable Development Program for the Mining Industry. Australian Government, Canberra, Australia.

BHPB, 2011. Our future: Sustainability report 2011. BHPB, Melbourne, Australia. 
Boutilier, R. G., 2014. Frequently asked questions about the Social Licence to Operate. Imp Ass Proj Appr, 32 , pp. 263-272.

Boutilier, R. G., Thomson, I., 2011. Modelling and measuring the SLO. In Invited paper presented at: The Social License to Operate Seminar. Brisbane: Centre for Social Responsibility in Mining. University of Queensland, 2011.

Martin Brueckner, M., Eabrasu, M., 2018. Pinning down the social license to operate (SLO): The problem of normative complexity. Res Pol, https://doi.org/10.1016/j.resourpol.2018.07.004

CSIRO, 2013. Social license to Operate: Minerals Down Under. CSIRO, Brisbane, Australia.

De Jong, W., Humphreys, D. 2016. A failed Social Licence to Operate for the neoliberal modernization of Amazonian resource use: the underlying causes of the Bagua tragedy of Peru. Fores, 89, pp. 552-564. http://dx.doi.org/10.1093/forestry/cpw033.

Dhaka Tribune, 2020. Road expansion project resumes, to alleviate commuter suffering. https:/www.dhakatribune.com/bangladesh/nation/2020/12/19/road-expansion-project-resumes-toalleviate-commuter-suffering (accessed: 22 May 2021)

Harvey, B., Bice, S. 2014. Social impact assessment, social development programmes and Social Licence to Operate: tensions and contradictions in intent and practice in the extractive sector. Imp Ass Proj Appr, 32, pp. 327- 335.

General Economics Division (GED), 2017. FY2016-FY2020: Accelerating Growth, Empowering Citizens (Final Draft). Planning Commission Government of the People's Republic of Bangladesh.

Jijelava, D., Vanclay, F. 2018. How a large project was halted by the lack of a Social Licence to Operate: testing the applicability of the Thomson and Boutilier model. Env Imp Ass Rev, 73, pp. 31-40.

Hanna, P., Vanclay, F., Langdon, E.J., Arts, J., 2016. Conceptualizing social protest and the significance of protest action to large projects. Extr Ind Soc, 3, pp. 217-239.

Hu, L. T., Bentler, P. M, 1999. Cutoff criteria for fit indexes in covariance structure analysis: Conventional criteria versus new alternatives. Structural equation modeling: a multidisciplinary journal, 6(1), pp. 155 .

Kurlander, L.T., 2001. Newmont mining: the social license to operate. Proceedings of the Global Executive Forum, University of Colorado Denver. [online] available at: www. ucdenver.edu/academics/InternationalPrograms/CIBER/GlobalForumReports/

Documents/Newmont_Mining_Social_License.pdf(accessed 20 May, 2021)

McNab, K., Onate, B., Brereton, D., Horberry, T., Lynas, D., Franks, D.M., 2013. Exploring the Social Dimensions of Autonomous and Remote Operation Mining: Applying Social License in Design. CSIRO, Brisbane, Australia.

Meesters, M., Wostyn, P., van Leeuwen, J., Behagel, J. H., Turnhout, E., 2020. The Social Licence to Operate and the legitimacy of resource extraction. Curr Opin in Env Sust, 45, pp. 7-11.

Mitchell, P. Top 10 Business Risks and Opportunities - 2020. Ernst \& Young Global Mining \& Metals Leader. [online]. Available at: https://www.ey.com/en_gl/mining-metals/ 10-business-risks-facing-mining-andmetals 2019 (accessed: 20 June 2020).

Moffat, K., Zhang, A. 2014. The paths to social license to operate: An integrative model explaining community acceptance of mining. Res pol, 39, pp. 61-70.

Musiyarira, H. K., Shava, P., Dzinomwa, G. The Extractive Industries and Society. https://doi.org/10.1016/j.exis.2020.05.020

Owen, J., Kemp, D. 2013. Social licence and mining: a critical perspective. Res Pol, 38(1), pp. 29-35. http://dx.doi.org/ 10.1016/j.resourpol.2012.06.016.

Slack, K., 2009. Mining Conflicts in Peru: Condition critical. Oxfam America, Boston.

Thomson, I., Boutilier, R. G., 2011. Social license to operate. SME min engg handbook, 1, pp. 1779-1796.

Vanclay, F. 2017. Principles to gain a Social Licence to Operate for green initiatives and biodiversity projects. Curr Opin Environ Sust, 29, pp. 48-56.

(C) 2021 the Authors. Journal of Engineering Science published by Faculty of Civil Engineering, Khulna University of Engineering \& Technology. This is an open access article under the terms of the Creative Commons AttributionNonCommercial-NoDerivatives License, which permits use and distribution in any medium, provided the original work is properly cited, the use is non-commercial and no Modifications or adaptations are made. 